\title{
Minimally invasive atlantoaxial fusion: cadaveric study and report of 5 clinical cases
}

\author{
Umesh Srikantha, MCh, Kiran S. Khanapure, MCh, Aniruddha T. Jagannatha, MCh, \\ Krishna C. Joshi, MCh, Ravi G. Varma, MCh, and Alangar S. Hegde, MCh
}

M. S. Ramaiah Medical College and Hospitals, Bengaluru, Karnataka, India

\begin{abstract}
OBJECTIVE Minimally invasive techniques are being increasingly used to treat disorders of the cervical spine. They have a potential to reduce the postoperative neck discomfort subsequent to extensive muscle dissection associated with conventional atlantoaxial fusion procedures. The aim of this paper was to elaborate on the technique and results of minimally invasive atlantoaxial fusion.
\end{abstract}

\begin{abstract}
MATERIALS Minimally invasive atlantoaxial fusion was done initially in 4 fresh-frozen cadavers and subsequently in 5 clinical cases. Clinical cases included patients with reducible atlantoaxial instability and undisplaced or minimally displaced odontoid fractures. The surgical technique is illustrated in detail.
\end{abstract}

RESULTS Among the cadaveric specimens, all C-1 lateral mass screws were in the correct position and 2 of the $8 \mathrm{C}-2$ screws had a vertebral canal breach. Among clinical cases, all C-1 lateral mass screws were in the correct position. Only one C-2 screw had a Grade 2 vertebral canal breach, which was clinically insignificant. None of the patients experienced neurological worsening or implant-related complications at follow-up. Evidence of rib graft fusion or C1-2 joint fusion was successfully demonstrated in 4 cases, and flexion-extension radiographs done at follow-up did not show mobility in any case.

CONCLUSIONS Minimally invasive atlantoaxial fusion is a safe and effective alternative to the conventional approach in selected cases. Larger series with direct comparison to the conventional approach will be required to demonstrate clinical benefit presumed to be associated with a minimally invasive approach.

http://thejns.org/doi/abs/10.3171/2016.5.SPINE151459

KEY WORDS atlantoaxial fusion; C1-2 fusion; minimal access; minimally invasive spine surgery; tubular retractor; cervical

$\mathrm{P}$ OSTERIOR atlantoaxial fixation was first described in 1910 by Mixter and Osgood, who used a braided silk thread..$^{20}$ This concept has gradually evolved into more biomechanically stable modifications to the present day polyaxial screw-rod constructs.

Conventional C-1 lateral mass screw and C-2 pedicle screw placement, as initially described by Goel and Lahiri, ${ }^{7}$ and later modified by Harms and Melcher, ${ }^{8}$ requires midline exposure from the occiput to $\mathrm{C} 3-4$ to enable sufficient lateral retraction of the posterior neck muscles and visualize the described entry points for screw placement.
This extensive muscular dissection causes disruption of the posterior musculoligamentous tension band, resulting in impaired postoperative neck muscle function, and may be responsible for persistent neck discomfort. $2,6,9,12,25$

Minimally invasive muscle splitting approaches, introduced for the lumbar spine, have the potential to significantly reduce muscle injury and preserve the posterior tension band. ${ }^{13,19}$ Their superiority in minimizing blood loss, reducing the duration of hospital stay, enabling earlier return to work, and improving functional outcomes compared with conventional procedures has been shown 
in several studies.,26 Recently, several reports of extension of this technique to the cervical spine have appeared in the literature and have shown promising outcomes. $6,16,21,28$

The present study elaborates minimally invasive $\mathrm{C} 1-2$ fusion performed using an expandable tubular retractor in 4 cadaver specimens and subsequently in 5 clinical cases.

\section{Methods}

Four fresh-frozen cadavers with an intact skull base and cervical spine and good visualization of the bony anatomy on fluoroscopy were selected for this study. Preoperative CT scanning was performed in all cadavers to note the dimensions and integrity of the $\mathrm{C}-1$ lateral mass and $\mathrm{C}-2$ pedicles. The $\mathrm{C}-1$ lateral mass and $\mathrm{C}-2$ pedicles in all cadavers were found suitable for placing a standard $3.5-\mathrm{mm}$ polyaxial screw. The same technique was then applied in a selected cohort of 5 clinical cases.

\section{Surgical Technique}

Similar steps were followed while performing the procedure in cadavers and clinical cases (Videos 1 and 2).

VIDEO 1. Surgical technique of minimally invasive atlantoaxial fusion being done on left side with preservation of the C-2 ganglion, intraarticular drilling, and graft placement within the $\mathrm{C} 1-2$ joint. Copyright Umesh Srikantha. Published with permission. Click here to view.

VIDEO 2. Surgical technique of minimally invasive atlantoaxial fusion being done on the right side with transection of the $\mathrm{C}-2$ ganglion, intraarticular drilling, and graft placement within the C1-2 joint. A portion of the video also shows the placement of an overlay split rib autograft between the $\mathrm{C}-2$ and $\mathrm{C}-1$ laminae and anchoring it with a titanium miniscrew. The access track through the muscle closing, once the tube is removed, and the skin wound are also shown toward the end. Copyright Umesh Srikantha. Published with permission. Click here to view.

A vertical $2.5-\mathrm{cm}$ incision was placed on either side $2.5 \mathrm{~cm}$ off the midline (Fig. 1A), and blunt soft-tissue dissection was done with artery forceps and a finger to palpate the inferior facet of C-2. The smallest dilator was introduced through the dissected plane and docked on the highest point of the C-2 facet (Fig. 1B). No effort was made at this point to palpate the posterior arch of $\mathrm{C}-1$, and care was taken not to dip the smallest dilator toward the $\mathrm{C} 1-2$ joint or medially into the gap between the C-1 posterior arch and C-2 lamina. Sequential dilation was then done (Fig. 1C) to finally place a 22-mm expandable tubular retractor (Quadrant system, Medtronic Sofamor Danek) overlying the C-2 lateral mass (Fig. 1D). The retractor was then angled superiorly, and the blades were expanded so as to cover the area between the posterior arch of C-1 and C-2 lateral mass, between the superior and inferior blades of the retractor. The inferior oblique muscle, which runs transversely in the C1-2 interlaminar space, was transected using cautery to expose the $\mathrm{C}-1$ posterior arch, posterior atlantoaxial membrane, and $\mathrm{C}-2$ pars. The posterior atlantoaxial membrane was then divided using sharp dissection to expose the underlying venous plexus. Further dissection was done in between the $\mathrm{C}-1$ and $\mathrm{C}-2$ lateral masses to expose the exiting $\mathrm{C}-2$ nerve root, $\mathrm{C} 1-2$ joint

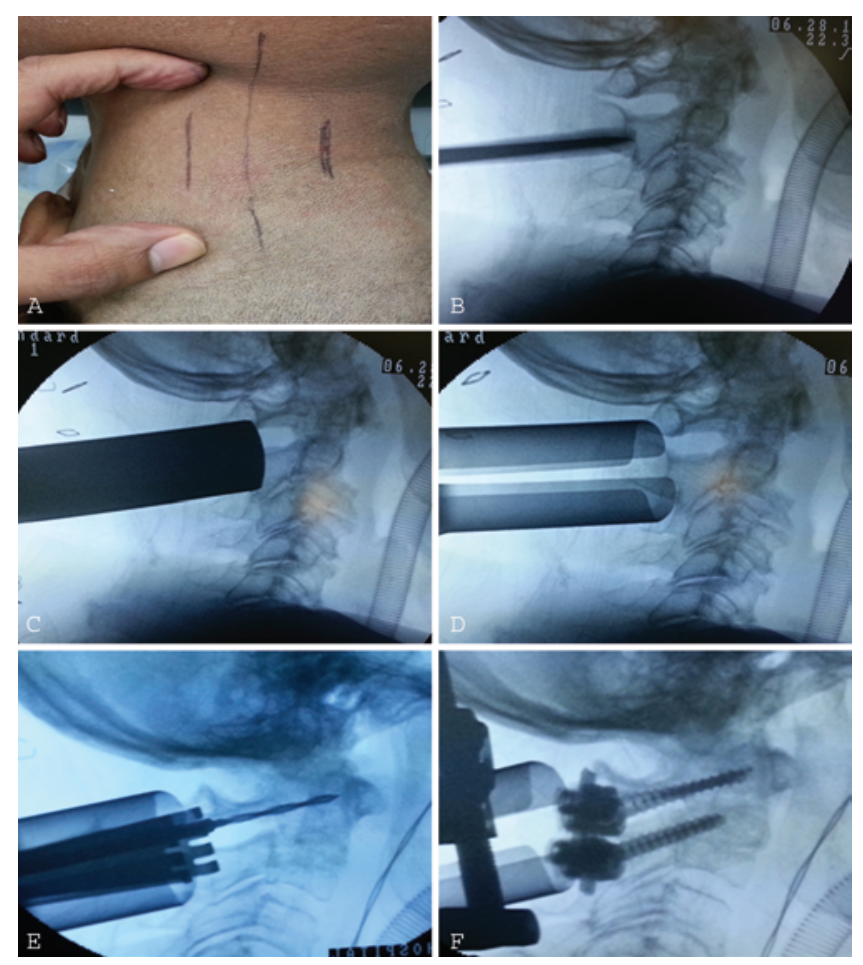

FIG. 1. A: Image showing the skin marking and stretch ability of the skin in the cervical region, allowing for a smaller incision. B-E: Intraoperative fluoroscopy images showing initial docking over the C-2 facet (B), after sequential dilation (C), placement of an expandable retractor (D), the $\mathrm{C}-1$ lateral mass drill hole being prepared $(\mathrm{E})$, and the final construct $(F)$. Figure is available in color online only.

space, and entry points for the C-1 lateral mass and C-2 pedicle screws. Any bleeding in clinical cases was controlled using bipolar cautery and Gelfoam. While using a C1-2 joint spacer (a trimmed wooden block was used as joint spacer in cadavers [Fig. 2C]), the C-2 nerve root was sacrificed if necessary; the joint space was distracted with the aid of a blunt Penfield dissector (Fig. 2A), the endplates were drilled using a diamond bur, and the graft was placed within the joint space. The C-1 lateral mass and C-2 pedicle screws were then placed with standard technique and instruments (Figs. 1E and F and $2 \mathrm{~B}$ ). The retractor had to be angled more superiorly to obtain the required trajectory for the C-2 pedicle screw. A connecting rod was placed under direct visualization. In some cases, a split rib graft was placed medial to the screw-rod construct (overlying the drilled cortical surfaces of the C-1 posterior arch and C-2 lamina), and was anchored with a miniscrew (Video 2). The retractor was removed, and similar steps were repeated on the other side.

\section{Results}

Placement of the screws was assessed in the 4 cadaveric specimens using postprocedural CT scanning (Fig. 2D-F). All 8 C-1 lateral mass screws were found to be in the correct position, with no breach into the medial or lateral cortices or into the adjacent joint spaces. Although not intentional, bicortical purchase was seen in 2 screws. 


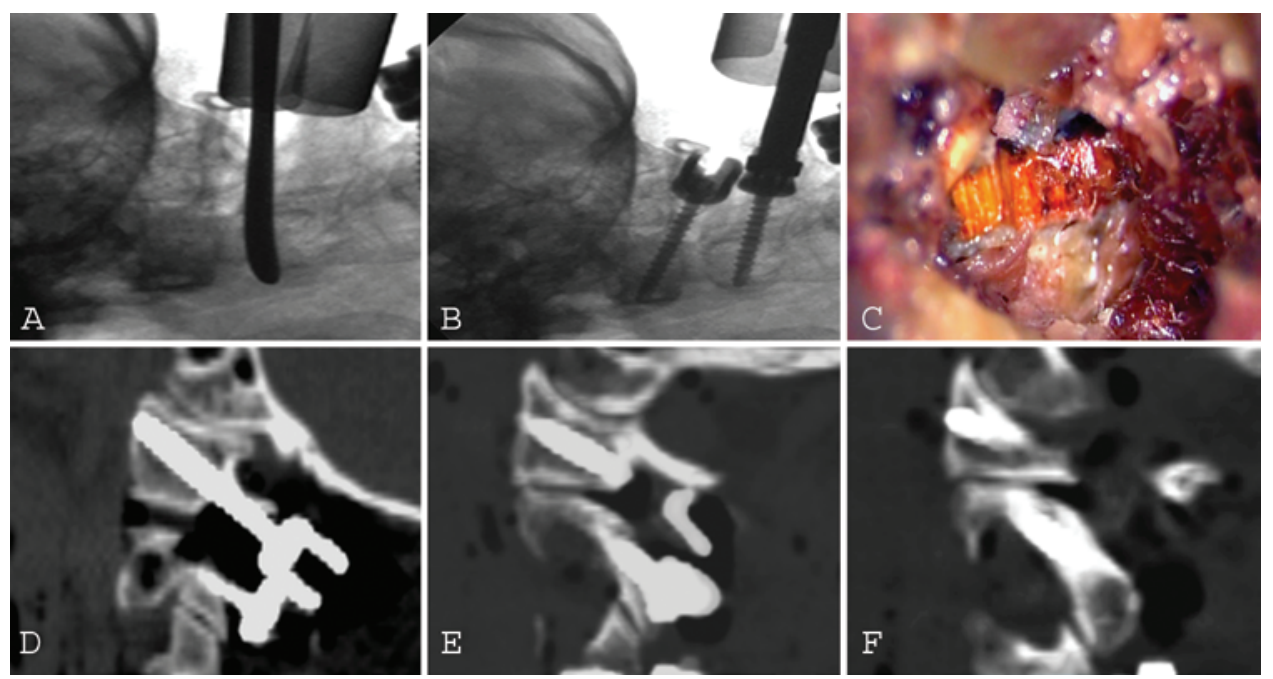

FIG. 2. Lateral fluoroscopy images obtained in a cadaver, showing a Penfield dissector within the C1-2 joint space (A) and final construct after placing C-1 and C-2 screws (B). A fashioned wooden block is positioned as a joint spacer (C). Postprocedural sagittal paramedian CT scans in the cadaver showing the position of the C-1 and C-2 screws (D-F). Figure is available in color online only.

Vertebral canal breach was seen in 2 of the $8 \mathrm{C}-2$ screws, one a Grade 1 breach and the other a Grade 2 breach. Both breaches were seen on the inferior aspect of the screw, possibly due to insufficient superior angulation.

Details of the clinical cases are given in Table 1. All C-1 lateral mass screws were in the correct position. Only one C-2 screw had a Grade 2 vertebral canal breach (among the 6 screws assessed using postoperative CT scans). In the remaining 2 cases, in which only a plain radiograph was obtained at follow-up, the position of the screws appeared satisfactory based on radiographic parameters in the assessment of the vertebral canal ${ }^{4}$ (Fig. 3). None of the patients had neurological worsening or implant-related complications at follow-up. Direct evidence of rib graft fusion or C1-2 joint fusion was successfully demonstrated in 4 cases (Fig. 4A and B); flexion-extension radiographs obtained at follow-up did not show mobility in any case (Fig. 4C and D).

\section{Discussion}

With the aim of reducing approach-related morbidity, minimally invasive spine surgeries have been gaining increasing importance over the last decade. ${ }^{2}$ Their role in reducing retraction-related devascularization and denervation of muscles and preserving the posterior midline tension band in both cervical and lumbar surgery has been emphasized in several studies. . $10,14,22,23$ In terms of clinical benefit, this would translate into lesser postoperative pain and analgesic usage, shorter hospital stay, earlier return to work, and better postoperative extensor muscle strength. ${ }^{15,19,26}$ Although minimally invasive techniques were initially popularized for the lumbar spine, these techniques are being increasingly applied in the cervical spine as well. Reports of minimally invasive techniques being used to treat common cervical procedures, such as laminoforaminotomy, ${ }^{3,29}$ lateral mass fusion, ${ }^{6,28}$ and stenosis decompression, ${ }^{21,24}$ can be found in the literature.
Application of minimally invasive techniques to perform an atlantoaxial fusion seems reasonable, as the steps of atlantoaxial joint manipulation, C-1 lateral mass, and C-2 pedicle/pars screw placement are all done from a lateral-to-medial trajectory and do not require exposure of midline structures. Of importance, this preserves muscular attachments of the C-2 spinous process, which act as stabilizers of the craniocervical junction, thus preventing postoperative loss of lordosis. ${ }^{2}$ This can be compared with transforaminal lumbar interbody fusion, in which a minimally invasive approach has shown considerable advantages over a conventional midline approach. ${ }^{17,18,26}$ The only muscle band that needs to be transected in a minimally invasive atlantoaxial fusion procedure is the inferior oblique muscle due to its anatomical position where it runs horizontally between the C-1 posterior arch and C-2 lamina. Since its function is to stabilize and aid in rotatory movements at the atlantoaxial segment, the impact of transecting this muscle is unlikely to affect outcome when an atlantoaxial fusion is being performed. Minimizing injury to the suboccipital muscles is the main advantage of this technique. We did not find a significant reduction in blood loss compared with conventional cases, as the main step where blood loss occurs in these procedures is during dissection around the $\mathrm{C}-2$ root and exposing the $\mathrm{C} 1-2$ joint space, which is no different from that of a conventional technique.

A few reports of minimally invasive atlantoaxial fusion published over the last decade can be found in the literature..$^{2,9,12,25}$ Using 12 fresh-frozen cadavers, Bodon et al. ${ }^{2}$ described the muscle splitting approach to the atlantoaxial joint in detail and were able to reach and identify the entry points for the C-1 lateral mass and C-2 pars screws in all the cadavers bilaterally. Joseffer et al. ${ }^{12}$ initially reported a case of os odontoideum that was successfully treated with a minimally invasive technique using an expandable tubular retractor, and later Holly et al., 9 from the same group, described the technique being used to treat 5 cases 
TABLE 1. Details of the clinical cases

\begin{tabular}{|c|c|c|c|c|c|}
\hline Variable & Case 1 & Case 2 & Case 3 & Case 4 & Case 5 \\
\hline Age/Sex & $46 / M$ & $68 / F$ & $22 / M$ & $37 / F$ & $52 / \mathrm{M}$ \\
\hline Clinical history & $\begin{array}{l}\text { Known case of RA for } \\
15 \mathrm{yrs} \text {; neck pain for } \\
5 \text { yrs; progressive } \\
\text { myelopathy for } 4 \text { mos }\end{array}$ & $\begin{array}{l}\text { History of RTA } 2 \text { mos } \\
\text { earlier w/ back } \\
\text { injury; treated for } \\
\text { head \& chest inju- } \\
\text { ries; neck pain }\end{array}$ & $\begin{array}{l}\text { History of RTA; severe } \\
\text { neck pain }\end{array}$ & $\begin{array}{l}\text { Underwent MRI for back } \\
\text { pain that revealed T12- } \\
\text { L1 PIVD. Incidentally } \\
\text { detected unstable AAI } \\
\text { w/ cord signal changes }\end{array}$ & $\begin{array}{l}\text { Neck pain for } 1 \mathrm{yr} ; \\
\text { progressive my- } \\
\text { elopathy for } 1 \mathrm{yr}\end{array}$ \\
\hline Diagnosis & AAI (reducible) & $\begin{array}{l}\text { Type III odontoid } \\
\text { fracture }\end{array}$ & Type II odontoid fracture & AAI (reducible) & AAI (reducible) \\
\hline Neurological status & Nurick Grade 3 & Nurick Grade 2 & Nurick Grade 2 & Nurick Grade 1 & Nurick Grade 3 \\
\hline mJOA score & 12 & 13 & 15 & 17 & 11 \\
\hline Details of procedure & $\begin{array}{l}\text { C-1 lateral mass/C-2 } \\
\text { pars fixation; rib graft } \\
\text { (joint+interlaminar) }\end{array}$ & $\begin{array}{l}\text { C-1 lateral mass/C-2 } \\
\text { pars fixation; rib } \\
\text { graft (interlaminar) }\end{array}$ & $\begin{array}{l}\text { C-1 lateral mass/C-2 } \\
\text { pars fixation; rib graft } \\
\text { (interlaminar) }\end{array}$ & $\begin{array}{l}\text { C-1 lateral mass/C-2 pars } \\
\text { fixation; (joint bone } \\
\text { substitute) }\end{array}$ & $\begin{array}{c}\text { C-1 lateral mass/C-2 } \\
\text { pars fixation (joint } \\
\text { bone substitute) }\end{array}$ \\
\hline $\begin{array}{l}\text { Duration of surgery } \\
\text { (mins) }\end{array}$ & 230 & 170 & 210 & 160 & 190 \\
\hline Blood loss (ml) & 400 & 250 & 300 & 150 & 200 \\
\hline $\begin{array}{l}\text { Duration of hospital } \\
\text { stay }\end{array}$ & 7 days & 5 days & 12 days & 7 days & 6 days \\
\hline FU duration (mos) & 24 & 15 & 26 & 16 & 14 \\
\hline Nurick grade at FU & 0 & 1 & 0 & 0 & 1 \\
\hline mJOA score at FU & 18 & 16 & 18 & 18 & 15 \\
\hline $\begin{array}{l}\text { Imaging findings } \\
\text { at FU }\end{array}$ & $\begin{array}{l}\text { CT: screws in correct } \\
\text { position; rib graft } \\
\text { fusion }\end{array}$ & $\begin{array}{l}\text { CT: screws in correct } \\
\text { position; rib graft } \\
\text { fusion }\end{array}$ & $\begin{array}{l}\text { CT: screws in correct } \\
\text { position; fusion at frac- } \\
\text { ture site \& rib graft }\end{array}$ & $\begin{array}{l}\text { X-ray: screws in situ; C1-2 } \\
\text { joint space fusion }\end{array}$ & $\begin{array}{l}\text { X-ray: screws in situ; } \\
\text { C1-2 joint space } \\
\text { fusion }\end{array}$ \\
\hline FU status & Asymptomatic; working & Asymptomatic & $\begin{array}{l}\text { Occasional neck pain; } \\
\text { working }\end{array}$ & Asymptomatic; working & $\begin{array}{l}\text { Asymptomatic; } \\
\text { working }\end{array}$ \\
\hline
\end{tabular}

$\mathrm{AAI}=$ atlantoaxial instability; FU = follow-up; $\mathrm{mJOA}=$ modified Japanese Orthopaedic Association; PIVD = prolapsed intervertebral disc; RA = rheumatoid arthritis; RTA $=$ road traffic accident.

of odontoid fracture with good results in all cases. Taghva et al. ${ }^{25}$ performed the procedure initially in 4 fresh-frozen cadavers and subsequently in 2 patients with odontoid fracture and described that the correct entry point for obtaining a lateral trajectory for placing screws was 3.5 $\mathrm{cm}$ lateral to midline. We followed a similar protocol in undertaking a cadaveric study prior to clinical application but found that an incision $2.5 \mathrm{~cm}$ lateral to the midline is more beneficial as it gives a more direct view of the $\mathrm{C} 1-2$ joint, prevents lateral placement of the tubular retractor, and also provides sufficient lateral angulation for placement of the screws.
As we have shown in the present series, in addition to placing $\mathrm{C}-1$ and $\mathrm{C}-2$ screws, minimal access to the $\mathrm{C} 1-2$ region does not limit routine methods used to achieve fusion. Intraarticular drilling, graft/spacer placement, and placement of an overlay interlaminar rib graft can all be performed with minimal access as well. These steps were adequately backed by the cadaver study done prior to the clinical series. With the availability of these steps, achieving fusion rates similar to those of conventional techniques should be possible even with minimally invasive techniques. In the present series, although direct evidence of fusion based on CT scanning findings was
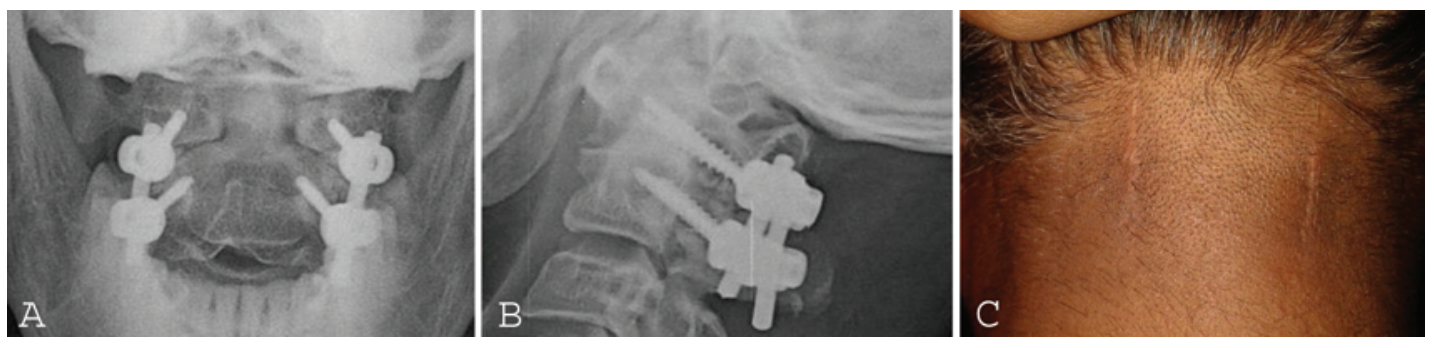

FIG. 3. A and B: Postoperative anteroposterior $(A)$ and lateral $(B)$ radiographs showing the position of the screws. C: Appearance of the wound at follow-up. Figure is available in color online only. 

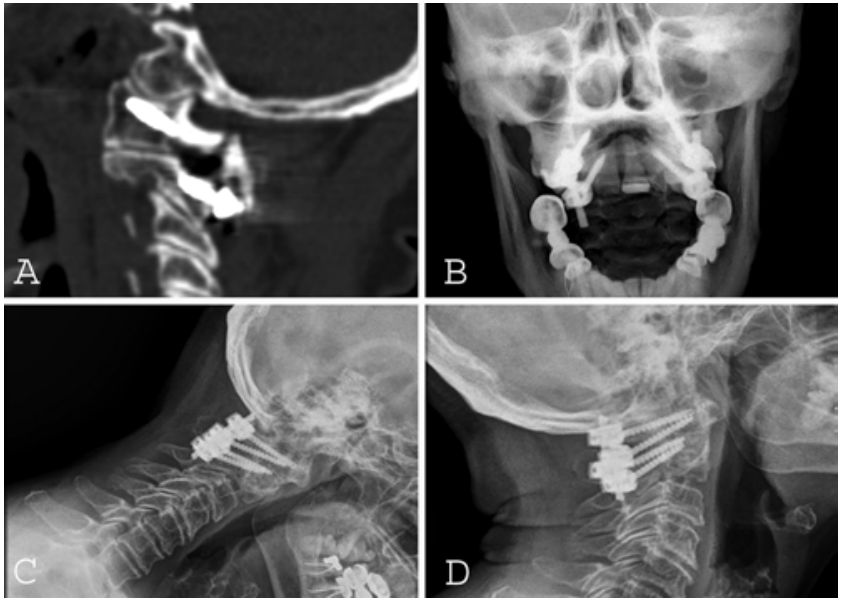

FIG. 4. Follow-up images in illustrative cases showing fused rib graft in a CT scan image (A, arrow) and fusion mass within the C1-2 joint space on an anteroposterior fluoroscopy image (B, arrow). Flexion (C) and extension (D) lateral radiographs obtained in a representative case, showing no mobility.

demonstrated in 3 of the 5 cases, dynamic radiographs in all patients did not show any mobility. However, it should be emphasized that cases with complex craniovertebral junction abnormalities that require bilateral simultaneous joint manipulation or added decompression in the form of foramen magnum decompression or $\mathrm{C}-1$ arch excision may not, in our opinion, be feasible for minimally invasive techniques. Similarly, posterior wiring techniques, which have been speculated to increase fusion rates, cannot be used in the minimal access route. ${ }^{27}$ In the present series, only cases of posttraumatic odontoid fracture with no cord injury or compression and reducible atlantoaxial instability were selected for treatment using minimally invasive techniques. This is one of the reasons for a small study group, which is the main drawback of the present study.

Application of minimally invasive techniques for atlantoaxial fusion has now crossed the boundary of technical feasibility. Despite minimally invasive approaches being increasingly used for treating diseases of the cervical spine as well as convincing rationale and theoretical evidence of their benefit over conventional approaches, there is a striking paucity of randomized studies comparing minimally invasive with conventional methods. A few studies comparing outcome between the approaches in cervical laminoforaminotomy have shown a marginal benefit for a minimally invasive approach over a conventional approach,, 329 which is more than one can say about a similar procedure in the lumbar spine, e.g., microlumbar discectomy. ${ }^{1,11}$ Future studies comparing minimally invasive and conventional techniques for more invasive procedures in the cervical spine might reveal more convincing benefit for a minimally invasive technique. Such studies are lacking at present.

\section{Conclusions}

The present study demonstrates the safety and efficacy in the application of a minimal access technique for atlantoaxial fusion, initially performed in 4 fresh-frozen cadavers and then in a small group of 5 carefully selected clinical cases. Further studies with larger patient numbers and direct comparison with conventional techniques are necessary to demonstrate the clinical benefit associated with minimally invasive approaches.

\section{References}

1. Arts M, Brand R, van der Kallen $B$, Lycklama à Nijeholt $G$, Peul W: Does minimally invasive lumbar disc surgery result in less muscle injury than conventional surgery? A randomized controlled trial. Eur Spine J 20:51-57, 2011

2. Bodon G, Patonay L, Baksa G, Olerud C: Applied anatomy of a minimally invasive muscle-splitting approach to posterior C1-C2 fusion: an anatomical feasibility study. Surg Radiol Anat 36:1063-1069, 2014

3. Clark JG, Abdullah KG, Steinmetz MP, Benzel EC, Mroz TE: Minimally invasive versus open cervical foraminotomy: a systematic review. Global Spine J 1:9-14, 2011

4. Ebraheim N, Rollins JRJ Jr, Xu R, Jackson WT: Anatomic consideration of $\mathrm{C} 2$ pedicle screw placement. Spine (Phila Pa 1976) 21:691-695, 1996

5. Fan S, Hu Z, Zhao F, Zhao X, Huang Y, Fang X: Multifidus muscle changes and clinical effects of one-level posterior lumbar interbody fusion: minimally invasive procedure versus conventional open approach. Eur Spine J 19:316-324, 2010

6. Fong S, Duplessis S: Minimally invasive lateral mass plating in the treatment of posterior cervical trauma: surgical technique. J Spinal Disord Tech 18:224-228, 2005

7. Goel A, Laheri V: Plate and screw fixation for atlanto-axial subluxation. Acta Neurochir (Wien) 129:47-53, 1994

8. Harms J, Melcher RP: Posterior C1-C2 fusion with polyaxial screw and rod fixation. Spine (Phila Pa 1976) 26:24672471,2001

9. Holly LT, Isaacs RE, Frempong-Boadu AK: Minimally invasive atlantoaxial fusion. Neurosurgery 66 (3 Suppl):193-197, 2010

10. Hosono N, Sakaura H, Mukai Y, Fujii R, Yoshikawa H: C3-6 laminoplasty takes over C3-7 laminoplasty with significantly lower incidence of axial neck pain. Eur Spine J 15:13751379,2006

11. Jacobs WCH, Arts MP, van Tulder MW, Rubinstein SM, van Middelkoop M, Ostelo RW, et al: Surgical techniques for sciatica due to herniated disc, a systematic review. Eur Spine J 21:2232-2251, 2012

12. Joseffer SS, Post N, Cooper PR, Frempong-Boadu AK: Minimally invasive atlantoaxial fixation with a polyaxial screw-rod construct: technical case report. Neurosurgery 58:ONS-E375, 2006

13. Kim CW: Scientific basis of minimally invasive spine surgery: prevention of multifidus muscle injury during posterior lumbar surgery. Spine (Phila Pa 1976) 35 (26 Suppl):S281S286, 2010

14. Kim DY, Lee SH, Chung SK, Lee HY: Comparison of multifidus muscle atrophy and trunk extension muscle strength: percutaneous versus open pedicle screw fixation. Spine (Phila Pa 1976) 30:123-129, 2005

15. Kotani Y, Abumi K, Ito M, Sudo H, Takahata M, Ohshima S, et al: Minimum 2-year outcome of cervical laminoplasty with deep extensor muscle-preserving approach: impact on cervical spine function and quality of life. Eur Spine $\mathbf{J}$ 18:663-671, 2009

16. Celestre PC, Pazmiño PR, Mikhael MM, Wolf CF, Feldman LA, Lauryssen C, et al: Minimally invasive approaches to the cervical spine. Orthop Clin North Am 43:137-147, x, 2012 
17. Wong AP, Smith ZA, Stadler JA III, Hu XY, Yan JZ, Li XF, et al: Minimally invasive transforaminal lumbar interbody fusion (MI-TLIF): surgical technique, long-term 4-year prospective outcomes, and complications compared with an open TLIF cohort. Neurosurg Clin N Am 25:279-304, 2014

18. Parker SL, Lerner J, McGirt MJ: Effect of minimally invasive technique on return to work and narcotic use following transforaminal lumbar inter-body fusion: a review. Prof Case Manag 17:229-235, 2012

19. Rahman M, Summers LE, Richter B, Mimran RI, Jacob RP: Comparison of techniques for decompressive lumbar laminectomy: the minimally invasive versus the "classic" open approach. Minim Invasive Neurosurg 51:100-105, 2008

20. Mixter SJ, Osgood RB: IV. Traumatic lesions of the atlas and axis. Ann Surg 51:193-207, 1910

21. Santiago P, Fessler RG: Minimally invasive surgery for the management of cervical spondylosis. Neurosurgery 60 (1 Supp1 1):S160-S165, 2007

22. Shiraishi T, Fukuda K, Yato Y, Nakamura M, Ikegami T: Results of skip laminectomy-minimum 2-year follow-up study compared with open-door laminoplasty. Spine (Phila Pa 1976) 28:2667-2672, 2003

23. Shiraishi T, Kato M, Yato Y, Ueda S, Aoyama R, Yamane J, et al: New techniques for exposure of posterior cervical spine through intermuscular planes and their surgical application. Spine (Phila Pa 1976) 37:E286-E296, 2012

24. Song JK, Christie SD: Minimally invasive cervical stenosis decompression. Neurosurg Clin N Am 17:423-428, 2006

25. Taghva A, Attenello FJ, Zada G, Khalessi AA, Hsieh PC: Minimally invasive posterior atlantoaxial fusion: a cadaveric and clinical feasibility study. World Neurosurg 80:414-421, 2013

26. Tian NF, Wu YS, Zhang XL, Xu HZ, Chi YL, Mao FM: Minimally invasive versus open transforaminal lumbar interbody fusion: a meta-analysis based on the current evidence. Eur Spine J 22:1741-1749, 2013

27. Tran M, Wadhwa R, Ziewacz J, Mummaneni P, Chou D: Comparison between C1-2 fixation with and without supplemental posterior wiring. Evid Based Spine Care J 5:12-15, 2014
28. Wang MY, Levi ADO: Minimally invasive lateral mass screw fixation in the cervical spine: initial clinical experience with long-term follow-up. Neurosurgery 58:907-912, 2006

29. Winder MJ, Thomas KC: Minimally invasive versus open approach for cervical laminoforaminotomy. Can J Neurol Sci 38:262-267, 2011

\section{Disclosures}

The authors report no conflict of interest concerning the materials or methods used in this study or the findings specified in this paper.

\section{Author Contributions}

Conception and design: Srikantha. Acquisition of data: Srikantha, Joshi. Analysis and interpretation of data: Srikantha, Jagannatha, Joshi. Drafting the article: Srikantha, Khanapure. Critically revising the article: Srikantha, Khanapure. Reviewed submitted version of manuscript: Srikantha, Varma, Hegde. Approved the final version of the manuscript on behalf of all authors: Srikantha. Administrative/technical/material support: Hegde. Study supervision: Varma, Hegde.

\section{Supplemental Information \\ Videos \\ Video 1. https://vimeo.com/168047525. \\ Video 2. https://vimeo.com/168047657.}

\section{Previous Presentations}

Portions of this work were presented as proceedings during the 2nd annual meeting of Minimally Invasive Spine Surgeons of India (MISSICON-2015) held on October 24 and 25, 2015, in Mumbai, India.

\section{Correspondence}

Umesh Srikantha, Department of Neurosurgery, M. S. Ramaiah Memorial Hospital, New Bel Rd., Bengaluru 560054, Karnataka, India.email: umeshsrikantha@gmail.com. 